\title{
The Effect of Customer Relationship Management on Customer retention in Private Higher Education Institute in Malaysia
}

\author{
Melissa Wane Manogharan \\ President College, \\ 16-1, Jalan Raja Laut, Kuala Lumpur, \\ 50400 Kuala Lumpur, \\ Federal Territory of Kuala Lumpur \\ melissa@president.edu.my \\ SoovendranVaradarajan \\ President College, \\ 16-1, Jalan Raja Laut, Kuala Lumpur, \\ 50400 Kuala Lumpur, \\ Federal Territory of Kuala Lumpur \\ soovendran@president.edu.my
}

\begin{abstract}
This research is conducted to evaluate the purpose of studying the customer relationship practices and customer satisfaction in Private Higher Education institutes (PHEI) in Malaysia that offers undergraduate degrees. According to the results obtained, it proves that CRM practices contain more positive effects on its customer satisfaction. The sample size used was only focused on PHEl that offer undergraduate programmes in Malaysia. According to the research conducted, there are few limitations that disclose the exact relationship between CRM and Customer Satisfaction. Education industry has become one of the major growing industries in Malaysia with various numbers of competitors. Thus, this study allows policy makers of PHEI to focus and implement CRM practices that would have an increase of direct positive impact of satisfaction for their customers. The study conducted also helps to evaluate not only CRM and satisfaction but also evaluate the effect of the Gender and Age Group factors that reflects on the relationship.
\end{abstract}

Keywords - Customer Satisfaction, Customer Relationship Management, Private Higher Education Institutions

Subject Classification: Business Management

Type (Method/Approach): Questionnaires, pilot-testing

Supporting Agencies: None

Language : English

Date of Submission : 2018-04-18

Date of Acceptance : 2018-04-27

Date of Publication : 2018-05-08

ISSN : 2278-7690

Volume : 09 Issue : 1

Journal : INTENATIONAL JOURNAL RESEARCH IN EDUCATION METHODOLOGY

Publisher : CIRWORLD

Website : https://cirworld.com

This work is licensed under a Creative Commons Attribution 4.0 International License. 


\section{Introduction}

The higher education environment in Malaysia has made many options and opportunities available for students to continue their studies beyond secondary education. In order to attain a competitive edge, higher education provider are required to find for effective and creative way to attract, retain and foster stronger relationships with their customers i.e. students. This scenario has somewhat created a marketing warfare among private organisations to attract as many students as possible. The fact that private institution does not have the "privilege" to receive any form of financial assistance from the government has made the quest to recruit and retain students harder (Hasan, 2009).

Customer relationship management (CRM) is growing as a part of business strategy and it is not the only tool used as a promotional tool in business organization (Ueno, 2006). Meanwhile this strategy maintains and sustains management in higher cognitive process, by evaluating information within the business which significantly allows the employment of technology. It is said that CRM could have been a theory that was established way back in 90's by the US. This method has been accepted, employed and applied in many wellestablished businesses throughout without any geographical limits and boundaries. CRM was solely based on the understandings of every organization that focuses on generating profit and targeting that will spear-head in facilitating the organization to retain their existing customers for a longer period of time. Therefore, it is clear that in recent times, Customer Satisfaction depends mainly on the 'significant service attributes' of the organization.

Predominantly with the pre-services and post-services delivered to the customer ensures the satisfaction level of the services obtained by customer. Moreover, it's necessary to observe and grasp the efficient services strategically provided for customer satisfaction, and this contributes the growth of the organisation (Lonial et al., 2015).

There are many ways of how an organization knows and distinguishes their customers from various perspectives and CRM is of the methods where it is a combination of marketing tools, technology and business processes (Chang 2010). Higher standard of services in return from the products or services that the customers purchase and it's essential to maintain the simple yet best customer service while developing and establishing in maintaining long-term relationships with the customers. CRM is a strategic component that allows the organization to handle their relationship with customers through the use of information, processes and technology where it can be inter-related with various departments within the organization such as sales, service, marketing and the support department (Kincaid 2003).

During the end of 90's there was a new term introduced call 'buzzword' where this phrase is associated today with the new term Customer Relationship Management (CRM). Whereby, this word or phrase is said to be relatively connected in with Enterprise Information System and Relational Marketing. CRM has allowed the organizations to compete aggressively among one another with higher product quality, advent of the data age, dynamical life designs and globalization were the major factors that contributed. Now, an organization makes sure that CRM is one of their main agenda with a relevant subject in the academic environment (Strandvik, et al., 2014).

\section{Materials and Methods}

\section{Problem statement}

Customer relationship management (CRM) is justified to balance the overall performance of the organization through obtaining, constructing, figuring out and retaining excellent relationship with customers (Haghshenaset al., 2015). The CRM strategy is now practiced by mostly all the organization in order to ensure they are always connected to their current and potential customers (Mohammad et al., 2013) and (Sin et al., 2005). In organizational concept, sustaining customer's satisfaction can be vital element and therefore it is advised that management focus on paying greater interest CRM. Organizations should take into consideration on how to cope and maintain customer's needs and wants and show some differentiation with their competitors on having effective relationship with their customers. By focusing on the demand of the customers, it ensures that the higher education sector will be able to enhance and improve satisfaction for students thus it ensures retention through a student-centred focus to increase loyalty (Seeman et al., 2006). Addressing and evaluating customer's needs guarantees the effective relationships with the organization and the customer. In order to identify, differentiate and then interact within customers to offer better service at all times customer service is the major factor which will initially contribute to retention (Berndt et al., 2005).

PHEI are said to be very competitive with one another when it comes to recruiting students locally and internationally in their respective programmes. Based on the research done it is believed that PHEI spend a large amount of sum to make sure the achievement of recruiting. However, many PHEI seem to have a very low rate of student retention (Crosling et al., 2009). 
An efficient CRM strategy is required in order for an organization to retain, acquire and gain profit from customers. Technical and functional quality of their service is also one major contributing factor which can influence the overall perception of the quality of service that the customer expects (Grönroos, 1984) and (Gounaris S., 2005).

Private HEls in Malaysia admit that they do undertake several programmes to satisfy the requirements of their customers - the Students (Peiris, 2007). Despites all the efforts taken, there are many students who do not follow their required length of timeline in the institutions and with that it creates a much more difficult journey for all those institutions to retain the number of students.

There are many new PHEI given licenses to satisfy the excessive demand within the marketplace in Malaysia. Currently in Malaysia there is a fast increase of PHEI where to date there may be very constrained research in Malaysia to determine the effectiveness of CRM that is widely contributing to factor of Customer Satisfaction in PHEI. Therefore, a research must to be done to evaluate whether CRM practices on customer satisfaction and make suggestions to retain student relationship with the PHEls in Malaysia.

Basically Public universities are funded or subsidised with the aid from the government and absolutely operated based merit system. For example students studying an Engineering course at a Public University would cost around RM2000 a year. Meanwhile the same course would at least cost 10 times more. (https://www.thestar.com.my/opinion/letters/2017/07/17/financing-for-public-highereducation/\#5IQVvx8r8pMd5yTh.99.)

Accordingly, there are annoying competitions amongst those two classes of universities as non-public Universities need to appeal to and maintain the students due to the fact they are profit oriented Universities. (Arokiasamy, et al., 2009).

\section{CRM defines,}

"A comprehensive strategy correlating with methods that allows an organisation to acquire, spot, nurture profit and retain their customers by maintaining and building long-run relationships with the customers and in short it is called CRM," (Sin e al., 2005). CRM defined from Relationhip Marketing and is derived as CRM is the core value of strategies in Relationship Marketing, where it emphasises on building relationship with customers which turns into a particle application (Gummesson, 2002a, p. 3, 2004). Enhancing relationship with customers, organizations have endeavoured the CRM approach which has resulted in more positivity.

There were many students completed analysis on CRM but they completely have a different definition from their perspective. All the definitions are different and evolve within CRM and relationship marketing views, which debates the relationship of the supplier, buyer and therefore the edges that organizations accumulate, to the addition of what actually customers receive as their results of the relationship.

Having said, CRM would definitely be an essential idea to drill into every organization culture or system as one of their core strategies. The functioning definition of CRM for PHEI in terms of analysis would be the techniques used by the institutes for minimising the gap between the experiences and expectations of each student who are their customers and providing them with excellent service ensures the equitable relationship.

\section{Customer satisfaction}

Customer satisfactions for PHEI functions as the major analysis study and are read as the "Overall Satisfactory Level from the perspective of a customer towards the level of service provided during the total purchase of the customer". This is said because in the service industry, the customer satisfaction and the quality of services provided should be monitored from 2 different dimensions despite a product selling organisation (Lu et al., 2015).

Customer Satisfaction has been acknowledged as a vital part of every company's strategy within the marketing concept which ensures the market price and the key drive of a long term profit (Fornell et al., 1996).

Every customer ensures a contented feeling after comparing the product or services purchased with the expectation level that they had before obtaining the product or service (Sugiati et al., 2013). According to Kotler, there is a relationship between loyalty and satisfaction where it is stated that "a highly satisfied customer generally stays loyal longer, buys more as the company introduces new products/service and upgrade existing products, talk favourably about the company and its product/service, pay less attention to competing brands, and is less sensitive to price, provides product or service ideas to the company, and costs less than new customers because transaction is routine"(Kotler, Marketing Management Millenium Edition, 2000). 


\section{Literature Review}

The literature review focuses on the principles of CRM along with the customer's satisfaction and it will be discussed in this section.

- What products and services are offered currently, and in the future?

- What market are we focusing on?

- Which customer group are we focusing on?

- Which of those are of maximum create value to the organisation?

- What extra needs does the most valuable customer have? customers?

In what exclusive methods are we able to be dealing with our organization to deliver better to

\section{Research hypothesis}

Based on the literature review as mentioned above, these are the hypotheses constructed:

H1: $\quad$ CRM and Customer Satisfaction has a statistical significant relationship

H2: $\quad$ CRM and Customer Satisfaction's relationship is moderated by the age group of respondents

H3: $\quad$ CRM and Customer Satisfaction's relationship is also moderated by the gender os respondents

\section{Research methodology}

In the purpose to determine the reliability and validity of each dimension in the scale, questionnaire was used to gather statistics and it was provided to lecturers and senior management groups of five (5) PHEls in Malaysia. After viewing all the questions, corrections were made to the questionnaire and the perfect questionnaires validity became confirmed via the stated group. A populace of forty was selected to measure the reliability which is also the pilot test.

Based on forty (40) answered questionnaires, the Cronbach's alpha was calculated using the SPSS software. Whereby, there were eight CRM items that was used to measure and Customer Satisfaction (CS) was also measured using eight items. Every item in CRM and Customer Satisfaction (CS) was measured using a Likert scale of 1-5 where 1suggests 'strongly agree', and five suggests 'strongly disagree', to the question asked.

Table I and II presented explains the descriptive record collected for the correlation between the inter-object values and Cronbach Alpha results for CRM and Customer Satisfaction. Age group, Ethnicity, Education and Gender of the students were collected as the demographic statistics of the respondents to examine the reasonable impact of the relationship between CRM and Customer Satisfaction.

Table I: The Descriptive and reliability statistics of the items in the CRM construct

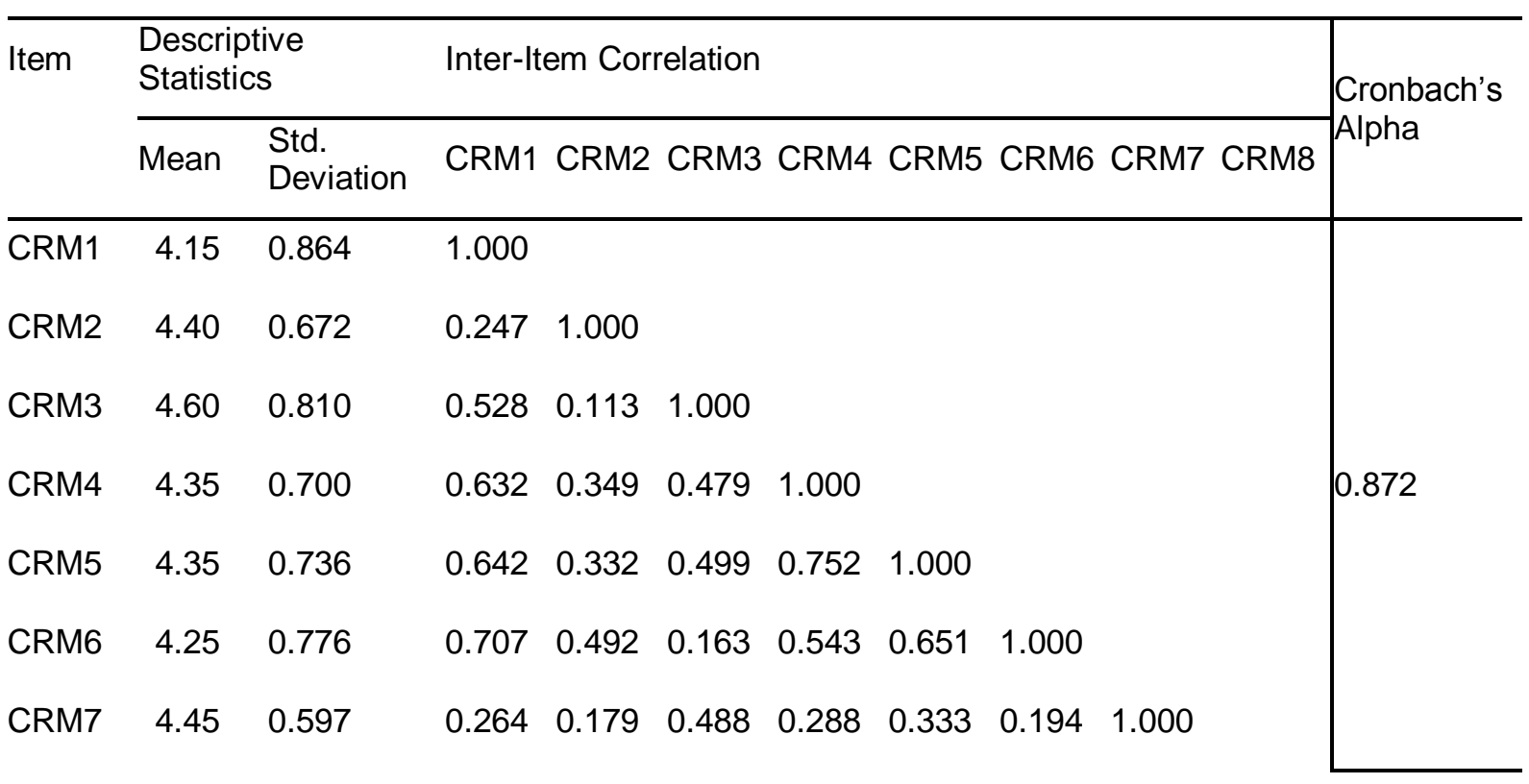


Table II: The Descriptive and reliability statistics of the items in the Customer Satisfaction construct

\begin{tabular}{|c|c|c|c|c|c|c|c|c|c|c|c|}
\hline \multirow[t]{2}{*}{ Item } & \multicolumn{2}{|c|}{$\begin{array}{l}\text { Descriptive } \\
\text { Statistics }\end{array}$} & \multicolumn{8}{|c|}{ Inter-Item Correlation } & \multirow{2}{*}{$\begin{array}{l}\text { Cronbach's } \\
\text { Alpha }\end{array}$} \\
\hline & Mean & $\begin{array}{l}\text { Std. } \\
\text { Deviation }\end{array}$ & CS1 & CS2 & CS3 & CS4 & CS5 & CS6 & CS7 & CS8 & \\
\hline CS1 & 4.33 & 0.888 & 1.000 & & & & & & & & \multirow{8}{*}{0.853} \\
\hline CS2 & 4.15 & 0.770 & 0.452 & 1.000 & & & & & & & \\
\hline CS3 & 4.23 & 0.733 & 0.397 & 0.302 & 1.000 & & & & & & \\
\hline CS4 & 4.15 & 0.802 & 0.577 & 0.669 & 0.290 & 1.000 & & & & & \\
\hline CS5 & 4.00 & 0.906 & 0.605 & 0.368 & 0.232 & 0.423 & 1.000 & & & & \\
\hline CS6 & 4.20 & 0.823 & 0.470 & 0.478 & 0.433 & 0.614 & 0.344 & 1.000 & & & \\
\hline CS7 & 4.18 & 0.747 & 0.569 & 0.444 & 0.160 & 0.426 & 0.492 & 0.317 & 1.000 & & \\
\hline CS8 & 4.20 & 0.758 & 0.510 & 0.431 & -0.037 & 0.413 & 0.523 & 0.181 & 0.571 & 1.000 & \\
\hline
\end{tabular}

The consistency and stability of the instrument measures the reliability and indicates the measurement index used is the Cronbach'salpha. The value of Cronbach's alpha is higher, where it is nearer to 1 (above 0.7), and is taken into consideration, as there's higher internal consistency reliability (Sekaranet al., 2009). The consistency and reliability of the findings will make sure, while, validity is concerned with whether or not the findings are in line with "what they are appear to be about." (Saunders et al., 2009).

Cronbach's Alpha value for the items, CRM1 to CRM8 was to test the reliability and the test result indicates that it was, 0.872 , which is more than 0.7 . Consequently, the items constructed are all reliable.

Cronbach's Alpha value for the items, CS1 to CS8 was to test the reliability and the test result indicates that it was, 0.853 , which is more than 0.7 . Consequently, this construct in the entire variable are highly reliable.

According to the data provided by Malaysian Qualification Agency (MQA) and the Ministry of Higher Education there are 509 PHEl's in Malaysia. They are divided into three categories: Colleges or Institutes (392), University College (39) and University (78). Currently there are almost 536,574 students active and studying in these PHEl.

The exact number of student enrolment in each semester may differ with one another. Thus, the average students in the 78 private Universities were calculated as the total population of students enrolment divided by total number of PHEl which comes up to 1054 . Therefore the total population of student at a given time in 78 University would be $82,212(1054 \times 78)$. Therefore this study was only focused in the Klang Valley region with 18 Universities and the population of students that consists 18,972 (1054×18).

It is essential to gather all the data that represents all the institutions in order to obtain more accurate results. Therefore it is also important and necessary to demonstrate a valid and significant result sample for the research conducted. (Sekaranet al., 2009), (Saunders et al., 2009), (Ranasingheet al., 2011).Collecting the entire data of a total populace of 18 universities offering undergraduate programmes was selected to run this research.

Using the random sampling method, with the population of 18,972 students whom are currently active studying in all $18 \mathrm{PHEl}$ was selected to collect data. The questionnaire consists of the level of study, and general demographic factors to simplify the research. With the sample of 500 students that was selected to 
assist in the sample from all the 18 Universities regardless of its quantity of enrolment. There were 200 questionnaires filled and returned but only 163 of those could be used for the research.

\section{Results and Discussion}

\section{Statistical analysis}

\section{Demographic summary}

To understand the respondents' status better demographic data was collected. The respondent's demographic data distribution is summarized in table III. Respondent's age within 18-24 were the majority based on the sample collected which is $68.7 \%$. The female respondents are more with $57.7 \%$ compared to the male respondents consisting $42.3 \%$. This statistic explains that the female students have higher enrolment compared to the male students in Malaysia.

Table III: The Demographic profile of respondents

\begin{tabular}{llll}
\hline & & Frequency & Percentage \\
\hline Gender & Male & 69 & 42.3 \\
& Female & 94 & 57.7 \\
\hline Age & $18-24$ & 112 & 68.7 \\
& $25-34$ & 42 & 25.8 \\
& $35-54$ & 9 & 5.5 \\
\hline
\end{tabular}

\section{Factor Analysis}

There are eight (8) factors contributing to the CRM directly. Table IV explains the Descriptive statistics and Inter-item correlation matrix for items in CRM. Based on table IV table, it explains the mean value for all the eight factors are more than 3 , which specifies that the students are displeased with the CRM practices provided by their PHEl's. Calculating the highest correlation for each of the item with at least one another item in the construct was between 0.5 and 0.7 . Hence, the entire items correlate adequately based on the data collected and the factor matrix for CRM is presented in table $\mathrm{V}$

Table IV - The Descriptive statistics and Inter-item correlation for items in the CRM

\begin{tabular}{lllllllllll}
\hline Item & \multicolumn{2}{l}{ Descriptive Statistics } & \multicolumn{2}{l}{ Correlation } & & & & & & \\
\cline { 2 - 11 } & Mean & $\begin{array}{l}\text { Std. } \\
\text { Deviation }\end{array}$ & CRM1 & CRM2 & CRM3 & CRM4 & CRM5 & CRM6 & CRM7 & CRM8 \\
\hline CRM1 & 3.2 & 0.847 & 1 & & & & & & \\
CRM2 & 3.39 & 0.651 & 0.193 & 1 & & & & & & \\
CRM3 & 3.62 & 0.803 & 0.549 & 0.118 & 1 & & & & & \\
CRM4 & 3.39 & 0.688 & 0.627 & 0.298 & 0.525 & 1 & & & & \\
CRM5 & 3.31 & 0.716 & 0.638 & 0.242 & 0.552 & 0.768 & 1 & & & \\
CRM6 & 3.24 & 0.736 & 0.674 & 0.463 & 0.165 & 0.572 & 0.619 & 1 & & \\
CRM7 & 3.43 & 0.588 & 0.295 & 0.144 & 0.532 & 0.335 & 0.295 & 0.175 & 1 & \\
CRM8 & 3.25 & 0.738 & 0.503 & 0.328 & 0.492 & 0.603 & 0.602 & 0.437 & 0.752 & 1 \\
\hline
\end{tabular}


Table V - A Factor matrix for items in the CRM construct

\begin{tabular}{|c|c|c|}
\hline Item Code & Items in the questionnaire & Factor Loading \\
\hline & The Institution.. & \\
\hline CRM1 & ...values students' satisfaction as an important factor. & 0.757 \\
\hline CRM2 & ...conducts student satisfaction surveys. & 0.353 \\
\hline CRM3 & ...maintains accurate and updated student records. & 0.627 \\
\hline CRM4 & $\begin{array}{l}\text {...is concerned about the facilities offered in the learning environment to the } \\
\text { students. }\end{array}$ & 0.814 \\
\hline CRM5 & ...maintains a continuous dialogue with students. & 0.823 \\
\hline CRM6 & ...listens and is sensitive to the needs and wants of students. & 0.681 \\
\hline CRM7 & ...has a process to monitor the relationships between staff and students & 0.604 \\
\hline CRM8 & ...has a group of officers who are responsible for new students enrolled & 0.804 \\
\hline
\end{tabular}

\section{Extraction Method: Principal Axis Factoring.}

According to factor analysis, KMO value was 0.662 where this is considered to be accurate and good. There was a single factor that was observed and $47.4 \%$ for the variations in all eight items in CRM. Whereby the minimum loading factor was calculated as 0.356 and the mean was calculated for all the eight items and stored and MCRM.

There are eight (8) factors contributing to the CS section. Table VI explains the Descriptive statistics and Interitem correlation matrix for items in the CS. Looking at the table, this explains the mean value for all the eight factors are more than 3 , which specifies that the students are displeased with the CS practices provided by their PHEl's. Calculating the highest correlation for each of the item with at least one another item in the construct was between 0.5 and 0.7 . Hence, the entire items correlate adequately based on the data collected and the factor matrix for CRM is presented in table VII

Table VI - The Descriptive statistics and Inter-item correlation for items of Customer Satisfaction

\begin{tabular}{lllllllllll}
\hline Item & \multicolumn{1}{l}{ Descriptive Statistics } & \multicolumn{2}{l}{ Correlation } & & & & & & \\
\cline { 2 - 11 } & Mean & $\begin{array}{l}\text { Std. } \\
\text { Deviation }\end{array}$ & CS1 & CS2 & CS3 & CS4 & CS5 & CS6 & CS7 & CS8 \\
\hline CS1 & 3.24 & 0.904 & 1 & & & & & & & \\
CS2 & 3.18 & 0.755 & 0.428 & 1 & & & & & & \\
CS3 & 3.19 & 0.735 & 0.332 & 0.251 & 1 & & & & & \\
CS4 & 3.18 & 0.795 & 0.588 & 0.619 & 0.238 & 1 & & & & \\
CS5 & 2.99 & 0.929 & 0.601 & 0.338 & 0.184 & 0.38 & 1 & & & \\
CS6 & 3.13 & 0.82 & 0.41 & 0.514 & 0.381 & 0.679 & 0.335 & 1 & & \\
CS7 & 3.2 & 0.724 & 0.608 & 0.444 & 0.195 & 0.368 & 0.529 & 0.322 & 1 & \\
CS8 & 3.18 & 0.747 & 0.524 & 0.416 & -0.085 & 0.406 & 0.548 & 0.155 & 0.53 & 1 \\
\hline
\end{tabular}


Table VII - The Factor matrix for items in the Customer satisfaction construct

Item Code Items in the questionnaire

Factor Loading

The Institution...

CS1 ...makes an effort to find out the needs of the students.

CS2 ...has processes to compile and integrate student data from all contact 0.667

CS3 ...has non-academic staff who maintain excellent relationships with students 0.323 CS4 has academic staff who provide the required services to satisfy student's 0.76
expectation

CS5 ...has a structure that is meticulously designed around student customers $\quad 0.66$

As a student, I... CS6 I. am satisfied with the "customised services" that I receive from the 0.667
Institution.

CS7

...have access to all information to monitor self-progress (such as 0.678
assignments, reading materials, grades and attendance records).

CS8 $\quad$...am satisfied with the helpfulness of staff in all departments.

0.636

\section{Extraction Method: Principal Axis Factoring.}

According to factor analysis, $\mathrm{KMO}$ value was 0.781 where this is considered to be accurate and good. There was a single factor that was observed and $42.3 \%$ for the variations in all eight items in CRM. Whereby the minimum loading factor was calculated as 0.320 and the mean was calculated for all the eight items and stored and MCS.

\section{Factor means by demographic}

Table VIII presents the descriptive statistic for the mean results for the gender domain. The P-value for the domains was more than 0.05 and it is presented in table VIII. This explains that there are no significant differences in the mean scores comparing male and female students based on all the items tested on the theoretical framework. This explains that the CRM and CS level that was tested proves the students are not happy with the relationship services provided by their PHEl's.

Table VIII - The Descriptive statistics of mean scores, by Gender

\begin{tabular}{llllll}
\hline Mean of construct & Gender & $\mathrm{N}$ & Mean & Std. Deviation & $\mathrm{p}$-value \\
\hline MCRM & Male & 69 & 3.1105 & 0.65253 & 7.022 \\
& Female & 94 & 3.5306 & 0.29653 & \\
\hline MCS & Male & 69 & 3.2252 & 0.51211 & 0.465 \\
& Female & 94 & 3.117 & 0.58309 & \\
\hline
\end{tabular}

Turkey HSD test was done for a multiple comparison between age groups and the results are tabulated in table X. As shown in table X, for the MCRM domain, the differences between mean is insignificant in the entire age group category. Thus, it can be concluded that there is no significant difference between CRM and the age group of students studying in PHEls in Malaysia. Nevertheless, the outcome is somewhat significant for the CS domain i.e. for the MCS domain, there exist a significant difference between mean in the entire age group category. But, it can be conclude that there is a significant difference between the age group of students and Customer Satisfaction. 
Table X - A Multiple comparison of MCRM and MCS - The Tukey HSD test

\begin{tabular}{|c|c|c|c|c|c|c|c|}
\hline \multirow{2}{*}{$\begin{array}{l}\text { Dependent } \\
\text { Variable }\end{array}$} & \multirow{2}{*}{$\begin{array}{l}\text { (I) } \\
\text { Group }\end{array}$} & \multirow{2}{*}{$\begin{array}{l}\text { Age }(\mathrm{J}) \\
\quad \text { Group }\end{array}$} & \multirow{2}{*}{$\begin{array}{c}\text { Age } \\
\text { Dean } \\
\text { Difference } \\
(I-J)\end{array}$} & \multirow{2}{*}{ Std. Error } & \multirow{2}{*}{ Sig. } & \multicolumn{2}{|c|}{ 95\% Confidence Interval } \\
\hline & & & & & & $\begin{array}{l}\text { Lower } \\
\text { Bound }\end{array}$ & $\begin{array}{l}\text { Upper } \\
\text { Bound }\end{array}$ \\
\hline \multirow[t]{6}{*}{ MCRM } & $18-24$ & $25-34$ & -0.01935 & 0.09496 & 0.977 & -0.244 & 0.2053 \\
\hline & & $35-54$ & 0.08879 & 0.18183 & 0.877 & -0.3414 & 0.5189 \\
\hline & $25-34$ & $18-24$ & 0.01935 & 0.09496 & 0.977 & -0.2053 & 0.244 \\
\hline & & $35-54$ & 0.10813 & 0.19277 & 0.841 & -0.3479 & 0.5642 \\
\hline & $35-54$ & $18-24$ & -0.08879 & 0.18183 & 0.877 & -0.5189 & 0.3414 \\
\hline & & $25-34$ & -0.10813 & 0.19277 & 0.841 & -0.5642 & 0.3479 \\
\hline \multirow[t]{6}{*}{ MCS } & $18-24$ & $25-34$ & $.37755^{\star}$ & 0.08909 & 0.000 & 0.1668 & 0.5883 \\
\hline & & $35-54$ & $.99561^{*}$ & 0.17059 & 0.000 & 0.592 & 1.3992 \\
\hline & $25-34$ & $18-24$ & $-.37755^{\star}$ & 0.08909 & 0.000 & -0.5883 & -0.1668 \\
\hline & & $35-54$ & $.61806^{*}$ & 0.18086 & 0.002 & 0.1902 & 1.0459 \\
\hline & $35-54$ & $18-24$ & $-.99561^{*}$ & 0.17059 & 0.000 & -1.3992 & -0.592 \\
\hline & & $25-34$ & $-.61806^{\star}$ & 0.18086 & 0.002 & -1.0459 & -0.1902 \\
\hline
\end{tabular}

*. The mean difference is significant at the 0.05 level.

\section{Regression analysis}

The simple linear regression analysis for MCRM and MCS ad the results are presented in table XI. MCRM is the important analyst for MCS and those are presented in XI, where the higher the value of MCRM is, the higher the MCS value is.

The higher the value of MCRM, the higher is the value on MCS. MCS=3.150+0.04 (MCRM), this is the regression equation calculated for the CRM on Customer Satisfaction.

Table XI - A Simple linear regression analysis of MCS upon MCRM

\begin{tabular}{llllll}
\hline Model & \multicolumn{2}{l}{ Unstandardised Coefficients } & $\begin{array}{l}\text { Standardised } \\
\text { Coefficients }\end{array}$ & $\mathrm{t}$ & Sig. \\
\cline { 2 - 4 } & $\mathrm{B}$ & Std. Error & Beta & \\
\hline (Constant) & 3.15 & 0.284 & & 11.079 & 0.000 \\
MCRM & 0.004 & 0.084 & 0.004 & 0.045 & 0.964
\end{tabular}

a. Dependent Variable: MCS.

\section{Discussion}

Based on all the results evaluated, it indicates that the relationship between CRM and CS are pretty strong. The finding explains that Customer Relationship Management is an important tool for all organization to practice and the organization is responsible to understand the expectations of their customers. In any organization, customer normally demand and prefer higher quality of service. Management of every organization should develop and incorporate the culture of monitoring customer's satisfaction and serving them better and thus this ensures a better profit growing for those organizations. Using CRM practices would be the ultimate strategic tradition in providing services to customers and this would move the organizations 
forward (Smith A. D., 2006). When loyalty is considered the major factor for all the organizations, there must be a special characteristic of service provided to customers compared to one's competitor. Providing unique services somehow correlates with loyalty of the customer where they are more attracted to your PHEl and they remain loyal to your organization in a long term. Having said, there are too many PHEI competitors in Malaysia and these PHEI should be more creative and innovative creating such specific characteristics for their services provided in PHEl in order to achieve the ultimate goals.

\section{Making the campus environment more conducive}

In the education system, students are the forefront. Education now seems to be more of a commercial transaction and this may sometimes lead to compromising the goals of education when there is a loss of concentration and focus on customers in a long-term learning environment, whereby the attention between the lecturer and the student becomes lesser as well(Schwartzman, 2000). Education is an intangible nature where the importance to treat education as a service should be implied by all PHEI. In a PHEI, students are their major consumers and they are supposed to be the beneficiaries for the services provided by the PHEI. Secondly, the parents or guardians become the indirect consumers for the service, and they are also known as one of the key stakeholders. The "receivers and participators" of a PHEI are the students (Zhang et al., 2008).

Based on the research, the environment of the campus entirely assists in improving the work efficiency and it ensures the overall happiness of their stakeholders. According to Aljerf\&Choukaife (2016), with the current globalization, competitiveness of PHEl the accelerating expansions it is vital and advisable for the management of these institutes to take several actions. For example, the management should improve the quality assurance framework and make changes in the current established frameworks that will allow and guarantees the persistence of the education quality in the PHEI without compromising the quality of graduates as the outcome of the PHEls.

Every student from any PHEI should be treated as the priority customer because they normally expect value for the money that they are actually paying for their education. The services provided by the PHEI should meet the requirement of the customers (students) to ensure they have gained value for the money spent. Implementing CRM as the utmost strategy ensures a guaranteed satisfaction among the customers and thus gaining the experience from customer's perspective as well as having greater profit and revenue for the PHEls.

\section{Using CRM as a corporate strategy}

Based on the research, it clearly states that CRM should be incorporated as one of the main corporate strategy in all the PHEl to enhance the satisfaction level of their customers and to maintain an excellent service quality. Building a unit that specifies on customer care in PHEI should be given importance by the management, where CRM practices should actually benefit all the students. This culture may create a trust within the students and it develops a sense of belonging for the students for the services provided by the PHEl for them. PHEI need to start using software that would allow them to collect students' data and use the CRM practices that can ensure the students' satisfaction is the paramount importance for a PHEI.

Through acquiring, building, identifying, and maintaining excellent relationships with students, CRM will ensure that these practices can enhance the performance of the organization. Since CRM enables and supports PHEI in understanding the expectation of their customers, the organization will be able to strengthen the relationship with the customers through efficient CRM practices. There should be a system where student's data can be integrated within each faculty and department of the PHEI at any given time. This platform of info-sharing system should create a platform where the staffs of the PHEI will be able to access student profiles and relevant details at any time and this gives a perception to the students that any staffs in the faculty or department has a common understanding about the background of the students. "Student Information System" is recommended in the findings and this should be implemented in all the PHEI in Malaysia.

\section{Success factor implies on Customer Satisfaction}

Customer service is the vital component of any organization when come to customer satisfaction. Differentiation, identifying and communicating with customers at any time ensures a better service and satisfaction to customers. Practising CRM as a core business strategy as a medium of support function and interaction with customers proves a satisfied needs for the customers. This allows the PHEI to take more initiative to understand the expectation of the different age group students and provide service needed accordingly. In marketing it is proven that word-of-mouth is the best way of promotion and having satisfied students will ensure them in recommending their PHEI to others and thus this indirectly support a sustainable growth for the organization. 
Providing the necessary technology support, design and building systems, developing a knowledge database, empowering and involving staffs should be recommended in all the PHEI in Malaysia which results in customer satisfaction indirectly. There should be a customer care culture cultivated in every employee of PHEI that matches the value system of the organization and directly guarantees a better service provided to their customers which ensures customer satisfaction.

There should be a regular basis of collecting student's satisfaction surveys that allows to organization to evaluate and monitor if the existing process and system is sufficient enough in meeting the student's expectation. When receiving the customer's feedback frequently, this will allow the PHEI to take any corrective measures before the issues are addressed. To avoid disappointments, PHEI should listen to the concerns from the students and provide them with sufficient support and this can be managed by the Student Service Department to further strengthen to mode of listening to student's needs.

In order to serve students better, PHEl should consider on the nature of their service provided to the students and complement those services with some tangible aspects within the study environment for the students. Services are intangible goods that customers purchase and therefore they tend to have comparison from the expectation of the consistent service provided at any given time where students await for the best classroom environment and facilities to be provided. In maintaining the professional outlook of their academic and nonacademic staffs, the PHEl should ensure the dress code of these employees are smart and professional as all these are the tangible aspects that the institutes can consider. Having said, the group that always look for changes are those fall under the socio-economic group. This is where the PHEI should focus on to monitor the behaviour and expectation level of customer segment within the age group of 18-24 years old. This is because; they are the pioneer customers of the PHEl currently in completing their Degree and meeting the industry demand for higher employability. Creating students whom have obtained knowledge and high level of skills will help those students in meeting those industry demands. The PHEl should take responsibility in understanding the student's mentality and address them adequately to the importance of earning a degree.

Meeting student's culture can vary these days compared to olden days. Students are now very much interested in spending most times in the respective institutes. Their lifestyle matters the most from the place they hang-out to the people they hang-out with. PHEI in Malaysia mostly offer undergraduate degree programmes which are conducted full-time where the students need to attend lectures almost five days a week. This is why the students ensure that they have facilities such as cafes, student lounge, coffee machines, Wi-Fi connection, play areas and comfortable seating areas in their PHEls. These facilities should be made compulsory in all PHEI to facilitate a much more comfortable and conducive learning environment for students.

\section{Customer care culture cultivated in all Employees}

The management of PHEl should ensure that the staffs are empathetic and responsive to the needs of their students. This is because; students always tend to frequently expecting for a staff member to attend to their problems at any time convenient to the student throughout their study schedule. This is why there should be a special unit focusing and handling only the needs and requirements of the students as they should not be limited to a fixed working hours as sometimes students may have problems after working hours, (which is 9am to 5pm in Malaysia). The students must have confident in the PHEI that they will be able to assist the student whenever they need support with the best service. This support concern should also be integrated by the academic staffs in delivering their services. Lecturers taking responsibility in making sure to maintain the academic quality without compromising the standards, attending and assisting the need of the student during lectures ensures a greater learning environment for the students.

\section{Conclusion}

CRM is a very strategic and powerful tool and all the PHEl should consider in implementing the CRM practices to enhance efficiency and retain customer satisfaction. This article was an in-depth review of how the relationship between CRM and Customer Satisfaction is achieved and thus retaining loyal customers. There are few PHEI implementing CRM practices but only at a very initial stage. PHEI must recognize the demand and need of their customers and make the CRM policies as a vital practice in PHEIs. Based on the student's perspective, it was very clear that the overall services provided by PHEI were very moderate and the institute continue for improvement.

Comparing the enrolment the graduate output of PHEI there is a significant difference. There is only about only $25 \%$ of graduates graduating each year (the student population at any given time to the output of the graduate). These sums a balance of $75 \%$ of the students are not eligible to graduate or did not complete the Degree course within the period. This phenomenon can be argued and it is said the satisfaction level or the service provided by the PHEI does not meet the required level of satisfaction of the student. There is no one 
specific reason of why this has affected the student's motivation and drive to complete the degree course. Thus, further research is recommended to obtain and understand the reasons behind this scenario. There should be also a remedial measurements recommended to solve the current anomaly.

These are some of the suggestions derived based on the results and finding obtained. Suggestions are directed to the higher level management and policy makers of any PHEI in Malaysia.

- $\quad$ Reduce the waiting time for the services by improving the service element

- $\quad$ All staffs of PHEI should take responsibility of using CRM is practices routinely to ensure that student satisfaction is considered as the paramount importance

- Having a high excellent quality of services allows the PHEI to maintain the student relationship

- Reward system financially and non-financially (e.g. motivation and financial reward) should be implemented for the employees that will ultimately reflect on the increase of customer satisfaction.

- $\quad$ Customer care training must be provided especially for those non-academic employees to ensure the quality of service that will be provided to treat the customers

With higher competition looming with the PHEI in Malaysia, institutions must consider in practicing and developing CRM strategies for the betterment of the institute which will eventually improve the profit in years. Job orientated qualifications are suggested in PHEI to match the increasing demand of the education industry. Students should be treated as a priority customer in the service of education industry which will directly result in higher customer satisfaction and retention. Moreover, PHEI should abide in the rule of marketing, where you offer the right product/service at the right time with the right standards.

To create a better understanding for the CRM dimensions, it is necessary that a research should be carried out with the PHEI staffs. This will ensure in creating and developing a higher standard of satisfaction which moves towards developing culture and tradition within. Qualitative data needs to be obtained in order to help and support the quantitative findings and this will allow a wider perspective for the service quality and standard for customer satisfaction. To suggest further improvement of the tertiary education system and the current practices, there should be an active involvement of the PHEls to obtain information on focusing a much more student-centred/orientated learning environment.

According to, Nikou, Seyedhossein\& Bin Selamat, Harihodin\&Che, Rasimah\&Yusoff, Mohd\&MalekalketabKhiabani, Mohsen (2016), CRM practices is said to be more of an evolution than revolution. Whereby, the use of CRM practices is allowing organization to gain more loyalty from customer. It advisable for service industries like PHIE to adapt and implement CRM practices in their business which allow them to increase and create customer loyalty and gain more profit or revenue.

With the current increasing level of demand for the qualified labour force in Malaysia, PHEls should take responsibility in producing qualified graduates that match the demand. The future of the Education sector in Malaysia will be soon based only on who complete their degrees in a full-time basis. Alumni's of very institutions will surely strengthen the value and quality of the PHEI and thus will enhance the loyalty level for the institute. Delivering high quality of service from the academic aspect will create an integrity level between the practices and the satisfaction of the students as the customer.

\section{References}

1. Arokiasamy, L., Ismail, M., Ahmad, A., \& Othman, J. (2009). Background of Malaysian private institutions of higher learning and challenges faced by academics. Journal of International Social Research 2(8), 60-67.

2. Aljerf, L., \&Choukaife, A.E. (2016). Sustainable development in Damascus University: A survey of internal stakeholder Views. Journal of Environmental Studies 2(2), 1-12. http://dx.doi.org/10.13188/2471-4879.100012

3. Berndt, A., Herbst, F., \& Roux, L. (2005). Implementing a customer relationship management programme in an emerging market. Journal of Global Business and Technology 1(2), 81 - 89.

4. Crosling, G., Heagney, M., \& Thomas, L. (2009). Improving student retention in higher education. Australian Universities' Review 51(2), 9-18.

5. Fornell, C., Johnson, M. D., Anderson, E. W., Cha, J., \& Bryant, B. E. (1996, October). The American customer satisfaction index: nature, purpose, and findings. Journal of Marketing, 60, 7 18.https://doi.org/10.2307/1251898

6. Gounaris, S. (2005). Measuring service quality in B2B services: an evaluation of the SERVQUAL scale vis-à-vis the INDSERV scale. Journal of Services Marketing, 19(6), 421-435. https://doi.org/10.1108/08876040510620193 
7. Grönroos, C. (1984). A service quality model and its marketing implications. European Journal of Marketing, 18(4), 36-44. https://doi.org/10.1108/EUM0000000004784

8. Gummesson, E. (2004). Return on relationships (ROR): the value of relationship marketing and CRM in business-to-business contexts. Journal of Business \& Industrial Marketing, 19(2), 136148.https://doi.org/10.1108/08858620410524016

9. Haghshenas, M., \&Ahmadi, S. M. (2015). The effects of customer relationship management dimensions on organizational performance (Case study: shipping organization of Iran). WALIA journal, 31(4), 134 - 141.

10. Hasan, H. F. A., llias, A., Rahman, R. A., \&Razak, M. Z. A. (2009). Service quality and student satisfaction: A case study at private higher education institutions. International Business Research, 1(3), 163.http://dx.doi.org/10.5539/ibr.v1n3p163

11. Kotler, P. (2000). Marketing Management Millennium Edition (10th, Custom Edition for University of Phoenix ed.). New Jersey: Pearson Custom Publishing.

12. Lonial, S., \&Raju, P. S. (2015). Impact of service attributes on customer satisfaction and loyalty in a healthcare context. Leadership in Health Services, 28(2), 149 - 166. https://doi.org/10.1108/LHS-122013-0045

13. Lu, C., Berchoux, C., Marek, M. W., \& Chen, B. (2015). Service quality and customer satisfaction: qualitative research implications for luxury hotels. International Journal of Culture, Tourism and Hospitality Research, 9(2), 168 - 182. https://doi.org/10.1108/IJCTHR-10-2014-0087

14. Mohammad, A. a., Rashid, B. b., \&Tahir, S. b. (2013). Assessing the influence of customer relationship management (CRM) dimensions or organization performance. Journal of Hospitality and Tourism Technology, 4(3), 228- 247. https://doi.org/10.1108/JHTT-01-2013-0002

15. Nikou, Seyedhossein\& Bin Selamat, Harihodin\&Che, Rasimah\&Yusoff, Mohd\&MalekalketabKhiabani, Mohsen. (2016). Electronic customer relationship management, customer catisfaction, and customer loyalty: A comprehensive review study. International Journal of Management and Economics Invention. 2. 1133-1144. https://doi.org/10.18535/ijmei/v2i12.02.

16. Peiris, C. N. (2007). Need for quality assurance and accreditation in Sri Lankan Universities. Quality assurance \& accreditation council of the University Grants Commission, Sri Lanka. www.education forum. Ik/wpcontent/uploads/2007/01/IDRC2_CountryPaper_SriLanka1.

17. Ranasinghe, S., \&Fonseka, M. (2011). Research in Management: A Guide to Practice (1st ed). Colombo 8: The Postgraduate Institute of Management.

18. Saunders, M., Lewis, P., \&Thornhill, A. (2009). Research Methods for Business Students (5th ed.). England: Pearson Education Limited.

19. Schwartzman, R., 1995. Are students customers? The metaphoric mismatch between management and education. Education, 116(2), pp.215-223.

20. Seeman, E. D., \& O'Hara, M. (2006). Customer relationship management in higher education: Using information systems to improve the student-school relationship. Campus-Wide Information Systems, 23(1), 24-34. https://doi.org/10.1108/10650740610639714

21. Sekaran, U., \&Bougie, R. (2009). Research Methods for Business (5th ed.). United Kingdom: John Wiley \& Sons Ltd.

22. Sin, L. Y., Tse, A. C., \&Yim, F. H. (2005). CRM: conceptualization and scale development. European Journal of Marketing, 39(11/12), 1264-1290.https://doi.org/10.5539/ibr.v6n11p29

23. Smith, A. D. (2006). CRM and customer service: strategic assets or corporate overhead? In Handbook of business strategy (87-93). Emerald Group Publishing Limited. https://doi.org/10.1108/10775730610618675

24. Strandvik, T., Holmlund, M. H., \&Grönroos, C. (2014). The mental footprint of marketing in the boardroom. Journal of Service Management, 25(2), 241-252.https://doi.org/10.1108/JOSM-01-20140033

25. Sugiati, T., Thoyib, A., Hadiwidjoyo, D., \&Setiawan, M. (2013, June). The role of customer value on satisfaction and loyalty (Study on hypermart's customers). International Journal of Business and Management Invention, 2(6), 65 - 70.

26. Teo, C. L. (2001). Realities of private institution. New Strait Time, 4.

27. Ueno, S. (2006). The impact of customer relationship management. USJP Occasional Paper 6-13, Harvard University.

28. Zhang, L., Han, Z., \&Gao, Q. (2008). Empirical study on the student satisfaction index in higher education. International Journal of Business and Management, 3(9), 46 51.http://dx.doi.org/10.5539/ijbm.v3n9p46. 